\title{
Tube Feeding in Stroke Patients: A Medical and Ethical Perspective
}

\author{
Jeff Blackmer
}

\begin{abstract}
Dysphagia, or difficulty swallowing, is a relatively common consequence following stroke, with most sources quoting rates of around $40 \%$. The percentage of stroke patients who require tube feeding for nutritional support varies quite widely, with studies quoting rates in the acute phase from $8.5 \%$ to $29 \%$. Since stroke patients are likely to constitute a high percentage of patients on a neurology or rehabilitation ward, neurologists and physiatrists are likely to be confronted with the sometimes challenging decision of whether and when to commence tube feeding and whether and when to discontinue it after it has begun. This decision-making process is likely to involve medical, ethical and legal considerations and the main purpose of this paper is to review these considerations and provide some practical recommendations.
\end{abstract}

RÉSUMÉ: Alimentation par gavage chez les patients qui ont subi un accident vasculaire cérébral: aspects médicaux et éthiques. La dysphagie, ou difficulté à avaler, est une conséquence relativement fréquente d'un accident vasculaire cérébral (AVC), le taux généralement rapporté étant d'environ de $40 \%$. La proportion des patients ayant subi un AVC, qui ont besoin d'une alimentation par gavage comme mode de soutient nutritionnel, varie considérablement. Certaines études font état de taux variant de $8.5 \%$ à $29 \%$ en phase aiguë. Comme les patients porteurs d'un AVC constituent habituellement une proportion élevée des patients hospitalisés dans un département de neurologie ou de réadaptation, les neurologues et les physiatres sont fréquemment confrontés à des décisions difficiles à prendre: doit-on commencer l'alimentation par gavage, quand doit-on le faire et quand doit-on l'arrêter si on l'a commencée? Ce processus décisionnel comporte des aspects médicaux, éthiques et légaux. Le but principal de cet article est de revoir ces aspects et d'énoncer des recommandations pratiques.

Can. J. Neurol. Sci. 2001; 28: 101-106

Mr. A is a 73-year-old male admitted to the neurology ward with a right hemisphere lacunar stoke resulting in pure left sided hemiplegia. While on the ward he suffers another, larger stroke. $\mathrm{He}$ is severely dysphagic and unable to communicate. He has no living will. His family demands that a feeding tube be placed.

Mrs. B, an 82-year-old female with a brain stem stroke, is admitted to the rehabilitation ward for equipment assessment and discharge planning. She has severe dysphagia as a result of her stroke and is at high risk for aspiration with oral feeding. She is widowed and has no close family or friends. Prior to her stroke she was living alone and had a self-described low quality of life. She is likely to be discharged to a long-term care home. While on the neurology service she had a percutaneous endoscopic gastrostomy tube placed. She now wishes to have it removed.

\section{DYSPHAGIAAND MALNUTRITION FOLLOWING STROKE}

The purpose of tube feeding following a stroke is to maintain adequate hydration and nutritional status in patients whose dysphagia makes it difficult or impossible to pursue oral intake.

Following a stroke, about $40 \%$ of patients experience dysphagia in the acute phase, ${ }^{1-4}$ and this percentage drops over time to $16 \%$ at one week and $2 \%$ at one month, according to one study. ${ }^{5}$ However, other studies have found dysphagia rates as high as $34 \%$ at one month and $33 \%$ at two months. ${ }^{4}$ These percentages seem to depend, at least in part, on the method used for assessing dysphagia (for example, bedside swallowing assessment versus modified barium swallow). Presumably they would also depend, to a significant degree, on the extent and location of the stroke, as well as the presence or absence of multiple infarcts. Larger strokes, bilateral strokes, brain stem strokes and multiple strokes would be more likely to result in dysphagia.

From the University of Saskatchewan, Department of Physical Medicine and Rehabilitation, Saskatoon City Hospital, Saskatoon, SK Canada ReCEIVED OCTOBER 17, 2000. ACCEPTEDin FinALFORM MARCh 12, 2001. Reprint requests to: Jeff Blackmer, University of Saskatchewan, Department of Physical Medicine and Rehabilitation, Saskatoon City Hospital, 701 Queen Street, Saskatoon, SK Canada S7K 0M7 
Dysphagia, along with the motor and perceptual difficulties seen following stroke, can put the patient at high risk for malnutrition and aspiration. The rate of malnutrition shortly after stroke varies from $16.3 \%{ }^{2}$ to $49 \%,{ }^{4}$ and studies have disagreed on whether this percentage increases or decreases over time. Regardless, dysphagia is consistently associated with a higher risk for malnutrition. ${ }^{4}$ Both dysphagia and malnutrition have been shown to be associated with poorer medical and functional outcomes following stroke. ${ }^{2,4,6}$ Therefore, the treatment of dysphagia and the prevention of malnutrition should be seen as very important medical issues in the overall management program provided for the stroke patient.

\section{TUBE FEEDING FOLLOWING STROKE}

Treatment for dysphagia can consist of dietary manipulation (pureed or dental soft diets), specific exercises and facilitation techniques (for example, lip, tongue and jaw exercises and the use of chin tuck or head turning to facilitate swallow) and surgical procedures. ${ }^{7}$ Common surgical procedures include insertion of a percutaneous endoscopic gastrostomy (PEG) tube or percutaneous gastro-jejunostomy (PGJ) tube. Medical indications for the insertion of feeding tubes include prevention of aspiration, prevention of malnutrition, maintenance of skin integrity and prolongation of life. ${ }^{8}$ Both types of tube are inserted through the abdominal wall into the digestive tract. The PEG tube rests in the stomach itself while the PGJ tube is advanced to the jejunum, with the theoretical advantage of decreasing the risk of aspiration.

Another option for tube feeding involves the nasogastric (NG) tube, which is passed directly through a nostril to the stomach. A study comparing NG with PEG tube feeding found that there was lower mortality in the PEG group, greater improvement in nutritional state and a shorter time until discharge. ${ }^{9}$ Because the PEG tube provides less of a noxious stimulus and is more difficult for the patient to dislodge, patients with a PEG tube required only one insertion while those with an NG tube required an average of six insertions. This study concluded that PEG tubes are preferred over NG tubes for the management of acutely dysphagic stroke patients.

Other advantages of PEG over NG tubes include a lower risk of tube blockage due to the larger diameter and the ability to more easily give bolus feeds as well as crushed tablets via the PEG tube. ${ }^{10}$ In general, physicians seem to reserve NG tubes for patients likely to require a short duration of enteral nutritional support and use PEG or PGJ tubes for longer-term feeding requirements. Institutional preferences and expertise may also play a role in the decision.

The choice between PGJ and PEG tubes is not always clear. One study ${ }^{11}$ suggested that lower esophageal sphincter manometry could serve as a guide to the optimal feeding route, with jejunostomy feeds indicated where lower esophageal sphincter pressure was low and gastrostomy feeds where lower esophageal sphincter pressure was normal.

Potential complications and side effects from tube feeding include aspiration pneumonia, wound infection, stomal leakage, tube migration or tube blockage. ${ }^{10}$ Other reported complications have included abdominal wall sepsis, peritoneal contamination, ulceration or necrosis of the gastric mucosa and diarrhea. ${ }^{1}$ Absolute contraindications to PEG tube insertion include inadvisable endoscopy, portal hypertension and ascites, and relative contraindications include a history of abdominal surgery, active peptic ulcer disease, bleeding disorders/anticoagulation, respiratory tract infection and marked cardiopulmonary disease. $^{12}$

The timing of tube insertion is somewhat controversial. Some authors recommend administration of intravenous fluids until swallowing can be assessed and if there is no swallowing capability after two to three days, then consider enteral feeding, presumably via NG tube. ${ }^{1}$ They feel there is little to recommend the use of PEG during the first few weeks poststroke since most patients will slowly improve over this time, and recommend PEG insertion only if no oral intake occurs after four weeks despite the efforts of the health care team. Allison and coauthors $^{10}$ agree that PEG feeding should be reserved for patients with persistent difficulties with swallowing of over four months duration. Where enteral nutrition is started within 72 hours, the length of stay may be significantly shortened compared with those who start enteral nutrition after 72 hours. ${ }^{13}$ O'Mahony and McIntyre ${ }^{12}$ feel that there is a broad agreement that PEG feeding is desirable if dysphagia is likely to persist for 14 days or longer but that it may be indicated in some patients after only 72 hours. However, there is not universal agreement, and others state that there is still no consensus about patient selection or timing of PEG insertion. ${ }^{14}$

\section{ETHICAL ISSUES}

In patients who are competent and agree to the insertion of a feeding tube which the physician feels is medically indicated, there is generally little controversy. Informed consent is obtained, and the tube is inserted. However, if the patient refuses, the physician may have trouble accepting this decision. The physician, and other members of the health care team, have a duty to try and help the patient and will be inclined to do what they feel is in the best interests of the patient (ie they would like to act according to the principle of beneficence). The patient, however, wants to control what is done to his or her body, and wants to be able to make an informed decision after discussions with the physician and other team members, as well as with family members and loved ones. The patient wants to maintain autonomy in the decision-making process. When the physician attempts to exercise beneficence at the expense of autonomy, there is the danger that the physician will act in a paternalistic manner. The same may be true in the situation where the competent patient wishes to discontinue a feeding tube that is already in place.

The situation is more complicated when making a decision of whether or not to insert or remove a feeding tube in the incompetent patient. A declaration of incompetence should occur only following a thorough evaluation by a trained professional. A patient may be competent to make some decisions but not others, and so his or her ability to decide specifically about tube feeding and life prolonging therapy should be assessed. If advance directives have been provided by the patient, they should be consulted. If the patient has appointed a substitute decision-maker, this person should become involved in the process, and if not, immediate family members should be consulted, such as the spouse, children and siblings. The question may become one of whether to institute artificial 
nutrition to prolong a life which might appear subjectively to have a low quality, in the absence of information obtained directly from the patient. Judgments regarding quality of life are difficult and, whenever possible, should be based on a knowledge of the previously expressed opinions and wishes of that individual patient. Many people have discussed with family members, in a general sense, how they would feel about life prolonging therapies if there were little or no hope of recovery. Some might feel strongly that life is worth preserving at any cost, and that any life is of a high enough quality to sustain. Others might disagree and be unwilling to maintain existence if, for example, the person could not enjoy previously pleasurable activities. Information obtained from family members and loved ones will be invaluable in this regard.

Even more difficult is the question of when to discontinue tube feeding in the incompetent or comatose patient. This decision has both legal and ethical ramifications and may ultimately become one of law rather than ethics. If an advance directive has been provided, and contains information specific to the situation, the decision may be relatively straightforward. However, if there is no documentation, and the family cannot recall previous discussions on this issue with the patient, there can be considerable controversy. There may be disagreement between the health care team and family members, and this is most likely to arise when the family wishes the tube feeding to be continued and the health care team feels that it should be discontinued. The issue might then become one of medical futility, where the health care team feels that further intervention would be medically pointless. Futility is a complex and somewhat controversial issue, and consultation with a bioethicist (or perhaps a lawyer) might be helpful in this regard.

\section{RELIGIOUS ISSUES}

The issue of religion and religious beliefs can certainly impact the decision-making process with regards to feeding tube insertion or removal. Although a review of all the various religious approaches to life-sustaining treatment is beyond the scope of this paper, religious preferences should be discussed and clarified with the patient and family members to ascertain exactly how they might influence treatment decisions. Whenever possible these preferences should, of course, be respected by the physician and members of the health care team.

One good example of religious affiliation influencing decision-making in this area is Judaism. It seems to be fairly clear that within the Jewish faith, prolonging life is more respectful than assuming that an incompetent patient wishes to end his or her suffering through the removal of a feeding tube. ${ }^{15}$ There is a duty to "cause to eat" that the Jewish tradition says should not be violated unless the patient is in the throes of dying. Thus a Jewish family might be especially adamant about continuing to pursue tube feeding in an incompetent patient to ensure they uphold the teachings and traditions of their religion.

\section{LEGAL ISSUES}

Most of the precedent-setting cases in this area have occurred in the United States. In the case of competent individuals, it seems clear that they have the right to refuse or discontinue artificial feeding. As Meisel states, ${ }^{16}$ there should be virtually no limitations for competent patients on forgoing artificial nutrition and hydration as is true of other life sustaining treatments. This was clear in the Bouvia case, ${ }^{17}$ where a competent 26 -year-old female with cerebral palsy was found to have the right to refuse forced feeding and to discontinue artificial nutrition and hydration. The court stated that "a patient has the right to refuse any medical treatment, even that which may save or prolong her life".

When the patient is incompetent and there is no information about their previously expressed desires, decision-making can be difficult. In the Conroy decision, ${ }^{18}$ which involved an 84 -yearold nursing home patient who was bedridden and minimally responsive, the New Jersey Supreme Court found that a substitute decision-maker is able to determine on behalf of the patient what the patient would have wanted if they were competent.

In the Barber case, ${ }^{19}$ artificial nutrition and hydration were discontinued in an incompetent patient based on the presumed best interests of the patient (there was some evidence that the patient may have previously expressed a desire not to be kept alive by machines). The physicians were charged with murder, but this charge was dismissed by the courts, who said that termination of artificial nutrition was an omission and not an act, and that the burden of treatment outweighed the benefits. The court also confirmed the right of the family to make the decision regarding life-sustaining treatment, guided by previously expressed wishes or the best interest of the patient.

The Cruzan decision in Missouri, in 1988, ruled that the state's "unqualified interest" in preserving human life superceded the family's decision to discontinue Nancy Cruzan's tube feedings, although she had been in a persistent vegetative state following a motor vehicle accident for over three years. ${ }^{20}$ She had previously stated to family members that she would not want to live if she could not be "at least half normal". The courts stated that nutritional support could only be withdrawn if there was "clear and convincing evidence" that she had authorized its termination before she lost decision-making capacity. This decision was upheld by the United States Supreme Court in a five to four decision, and is still the only right-to-die case to reach that level. Following this decision, many state legislatures actually enacted legislation to make it easier for physicians and families to discontinue artificial nutrition in incompetent patients. ${ }^{21}$ Meisel also notes that the Cruzan decision has had virtually no effect on the case law and that the courts have continued to permit the forgoing of artificial nutrition and hydration on the same basis as other treatments. ${ }^{21}$ In November 1990, more information became available about Nancy Cruzan's previously expressed wishes regarding life-sustaining treatment and a state judge subsequently authorized the removal of her feeding tube. She died 12 days later.

The O'Connor decision ${ }^{22}$ denied a guardian permission to authorize the removal of artificial nutrition and hydration, and affirmed prior New York precedents which held that no lifesustaining treatment may be forgone unless the patient had completed an advance directive to that effect.

The Washington Supreme Court, in a five to four decision, called into question the legitimacy of forgoing artificial nutrition. They decided in the Grant case ${ }^{23}$ that the parents of a terminally ill child had the authority to terminate artificial nutrition and 
hydration. However, the decision was later modified so as to find the withdrawal of artificial nutrition impermissible.

There have not yet been any relevant Canadian legal challenges in this area. It is unclear what effect these decisions might have on future Canadian cases, and physicians would be well-advised to obtain legal counsel if uncertain of the law in their area.

With respect to advance directives, most provinces now have legislation supporting their use. ${ }^{24-32}$ The legislation varies from province to province with regards to the actual scope of the advance directives, as well as who can act as substitute decisionmaker and the requirements for witnessing and procedures for activating the advance directive. ${ }^{33}$

In terms of substitute decision-making outside of an advance directive, nonstatutory law is rather uncertain. ${ }^{34}$ It appears that only a court-appointed guardian or the court itself have the legal power to make health care decisions on behalf of an incompetent adult; family members do not. ${ }^{35-37}$ However, in every day medical practice, family members are commonly consulted and are often viewed as having decision-making authority. ${ }^{34}$

\section{Policy ISSUES}

Early statements regarding the discontinuation of treatment were issued by the American Medical Association House of Delegates, which stated: "The cessation of the employment of extraordinary means to prolong the life of the body when there is irrefutable evidence that biological death is eminent is the decision of the patient and/or the immediate family. The advice and judgment of the physician should be freely available." 38

The American Academy of Neurology recognizes the provision of artificial nutrition as a medical treatment that may be withdrawn or withheld "in accordance with the practices and principles governing the withholding and withdrawing of other forms of medical treatment", and also states that "it is good medical practice to withdraw the artificial provision of fluids and nutrition when the patient's condition becomes hopeless". ${ }^{39}$ This view was affirmed and endorsed by the Council on Ethical and Judicial Affairs of the American Medical Association in $1990 .{ }^{40}$

The American Dietetic Association statements reflect the role of the dietician in ethical decision-making and suggest that providing emotional support to the patient may be more important than providing nutrients in some cases. ${ }^{41}$

\section{EMPIRICAL STUDIES}

Callahan and coworkers ${ }^{42}$ performed a prospective cohort study to examine the clinical decision-making process involved in PEG insertion from the perspectives of the patients, caregivers and physicians. They found that patients and caregivers reported multiple discussants, incomplete information and considerable distress in arriving at the decision to proceed with artificial feeding. They often perceived few alternatives to PEG feeding. Physicians reported considerable distress in arriving at recommendations to proceed with PEG feeding, including pressure from family members and other healthcare professionals. Only $60 \%$ of patients and caregivers felt they had enough time to discuss their decision with others and the same percentage felt they had insufficient information in order to make an informed decision. Interestingly, $8 \%$ of physicians did not feel that competent patients could refuse insertion of a feeding tube.

A mail survey of 439 Missouri family physicians ${ }^{43}$ conducted after the conclusion of the Cruzan case examined the relative importance of factors influencing physicians to use tube feedings in patients lacking decision-making capacity. Alarmingly, only $53 \%$ of physicians would oppose insertion of a feeding tube when the patient had an advance directive specifically directing them not to insert one. The family's opinion on the situation influenced the physician's decision. Physicians tended to endorse family preferences even if they were specifically opposed to the patient's advance directives.

A study at the University of Ottawa ${ }^{44}$ examined the factors involved in the decision to start long-term tube feeding in cognitively impaired older people (most of whom had suffered a stroke) from the perspective of the substitute decision-maker. It involved a telephone survey of 46 substitute decision-makers of patients who had a feeding tube inserted and found that most of the patients had not given advance directives and that only $56.5 \%$ of the substitute decision-makers were confident that the patient wanted to be tube fed. In $28.3 \%$ of cases, the physician did not even speak to the substitute decision-maker. Well under half the decision-makers felt that tube feeding improved the patient's quality of life and most indicated that they would not choose to be tube fed themselves.

These studies underline a concern that physicians may not always follow the patient's wishes as outlined in an advance directive or consult with a substitute decision-maker regarding advance directives or previously expressed wishes. There is an obvious risk of unilateral decision-making and paternalism by the physician in these situations.

\section{A PRACTICALAPPROACH TO DECISION-MAKING}

The decision on whether or not to insert a feeding tube will rest at least in part on the competency status of the patient. In patients who are competent to decide for themselves, the physician and health care team should provide them with the information necessary to reach an informed decision, including the risks and benefits of the procedure, alternatives to the procedure (such as parenteral nutrition, intravenous fluids or NG tube feeding) and the long-term implications of feeding tube insertion. Time should be given for the patient to discuss the situation with family members and loved ones. The patient's decision, once made, should be respected and they should be clearly informed of the right to change their mind in the future. Family members should be offered support as there is often a concern that their loved ones will be "starved" - it should be explained that the patient will be kept as comfortable as possible, and is unlikely to suffer.

In competent patients with a feeding tube who wish to have the tube discontinued, again the decision should be left to the patient. If, after it is clear that they understand the implications of their decision and the alternatives available to them, they still wish to have the tube removed, their request should be respected. Patients should again be given all the information necessary to make a properly informed decision. When tube feeding is not chosen, or is discontinued, a referral to the palliative care service might be appropriate, depending on the clinical situation. 
Measures can be taken there to ensure the ongoing comfort of the patient and support for family members.

The situation may become more difficult in the incompetent patient. If the patient has provided an advance directive, it should be consulted to see if it contains instructions on artificial nutrition or other life-sustaining therapies. If it is clear from this document what the patient's wishes would be in this situation, these wishes should be followed. If no advance directive exists, the substitute decision-maker or closest family member should be consulted. They should be given all relevant information, as would be done for the competent patient. Their decision should be based first on the previously expressed wishes of the patient regarding this particular situation, and in the absence of this, on the patient's best interests. Determining the best interests of the patient is usually based on weighing the burdens and benefits of the treatment. If a substitute decision-maker is not available then one may be appointed by the courts to try and determine the patient's best interests. If the health care team has strong opposition to the decisions made by the family or substitute decision-maker, such as a decision to continue tube feeding in the face of medical futility, then further communication and clarification may be required, and on occasion intervention by the courts may become necessary. If a compromise or decision cannot be reached, then transfer of the patient's care to another physician or facility may become necessary.

From a legal standpoint, the most difficult situation may be that of the incompetent patient where the family and/or caregivers wish to remove the feeding tube in the absence of an advance directive or clearly expressed previous wishes. If the physician and family agree that the tube should be removed, then the physician can make a medical recommendation to this effect. However, it would likely be prudent to speak with a lawyer representing the health care facility to acquire further information about the possible legal ramifications of this action in their particular locale. This information will need to be taken into account by both the physician and family in reaching their final decision on what action should be taken.

\section{SUMMARY}

The issue of starting or discontinuing tube feeding following a stroke is often straightforward and uncontroversial. However, because of the fundamental importance of nutrition and hydration, both medically as well as psychologically, there exists the potential for significant disagreement between members of the health care team, the patient and members of the patient's family. At times these decisions can literally have life and death implications.

Decisions in this area should involve a consideration of ethical as well as legal issues. When possible, relevant policies and guidelines, both institutional and professional, may be of assistance. Competent, autonomous patients should be allowed to direct their own care after receiving all relevant information. The case of incompetent patients is often more complicated, and generally involves reference to living wills (where available) or previously expressed wishes. In the absence of these, family members and loved ones will need to be involved in the decisionmaking process, as will members of the health care team. In cases of unresolvable conflict, consultation with a bioethicist or lawyer may become necessary.

\section{THE CASES}

Mr. A's family likely requires further information on the situation. They should be informed of the benefits and risks of tube feeding as well as long-term implications and alternatives to placement of a feeding tube (eg. parenteral nutrition, NG tube feeds, intravenous fluids). They should be informed of the specific prognosis in Mr. A's case, and whether there is a reasonable chance for further recovery. If there is no chance for further recovery, Mr. A's quality of life in the current situation should be examined by the family and health care team. Mr.A's previously expressed wishes regarding artificial nutrition and other life-prolonging therapies should be explored. In the end, the health care team should assist the family in making a decision that will be in the best interests of Mr. A. If there is little chance for further improvement they may want to consider other options besides PEG placement. If there is a good chance of improvement, they may want to consider a trial of NG feeding while waiting to see if the clinical situation changes, and consider PEG feeding if the patient improves clinically but continues to be dysphagic.

Mrs. B is a competent, autonomous patient who is requesting discontinuation of her tube feeds. She should be provided with comprehensive information regarding the possible implications and consequences of this decision, including the possibility of death. She should be assessed for symptoms of depression, and it should be treated if present. If she continues to request that the tube be removed, her wishes should be respected. If she wants to pursue oral feeding, despite the risks, she should also be allowed to do so.

\section{REFERENCES}

1. Powell-Tuck J, van Someren N. Gastrostomy feeding for patients with stroke and bulbar palsy. JR Soc Med 1992; 85: 717-719.

2. Davalos A, Ricart W, Gonzalez F, et al. Effect of malnutrition after acute stroke on clinical outcome. Stroke 1996; 27: 1028-1032.

3. Kong K, Chua K, Tow A. Clinical characteristics and functional outcome of stroke patients 75 years old and older. Arch Phys Med Rehabil 1998; 79: 1535-1539.

4. Finestone H, Greene-Finestone L, Wilson E, at al. Malnutrition in stroke patients on the rehabilitation service and at follow-up: prevalence and predictors. Arch Phys Med Rehabil 1995; 76: 310-316.

5. Barer DH. The natural history and functional consequences of dysphagia after hemispheric stroke. J Neurol Neurosurg Psychiatry 1989; 52: 236-241.

6. Gariballa S, Parker S, Taub N, et al. A randomized, controlled, single-blind trial of nutritional supplementation after acute stroke. J Parenter Enteral Nutr 1998; 22: 315-319.

7. Noll S, Bender C, Nelson M. Rehabilitation of patients with swallowing disorders, in Braddom R ed. Physical Medicine and Rehabilitation, WB Saunders and Co, Philadelphia, 1996:533554.

8. Mitchell S, Kiely D, Lipsitz L. The risk factors and impact on survival of feeding tube placement in nursing home residents with severe cognitive impairment. Arch Intern Med 1997; 157: 327-332.

9. Norton B, Homer-Ward M, Donnelly M, et al. A randomized prospective comparison of percutaneous endoscopic gastrostomy and nasogastric tube feeding after acute dysphagic stroke. BMJ 1996; 312: 13-16.

10. Allison C, Morris A, Park R, et al. Percutaneous endoscopic gastrostomy tube feeding may improve outcome of late rehabilitation following stroke. JR Soc Med 1992; 85: 147-149.

11. Lucas C, Yu P, Vlahos A, et al. Lower esophageal sphincter 
dysfunction often precludes safe gastric feeding in stroke patients. Arch Surg 1999; 134: 55-58.

12. O'Mahony D, McIntyre A. Artificial feeding for elderly patients after stroke. Age Ageing 1995; 24: 533-535.

13. Nyswonger G, Helmchen R. Early enteral nutrition and length of stay in stroke patients. J Neurosci Nurs 1992; 24: 220-223.

14. Wanklyn P, Cox N, Belfield P. Outcome in patients who require a gastrostomy after stroke. Age Ageing 1995; 24: 510-514.

15. Goldsand G, Rosenberg ZR, Gordon M. Bioethics for clinicians: 22. Jewish bioethics. CMAJ 2001; 164: 219-222.

16. Meisel I. The Right to Die, Vol 2. Wiley Law Publications, New York. 1995. p. 602.

17. Bouvia v. Superior Court (Glenchur) 225 Cal. Rptr. At 305.

18. Conroy, 486A2d 1209, NJ 1985.

19. Barber v. Superior Court, 195 Cal. Rptr. 484 (Ct. App. 1983).

20. Cruzan v. Harmon, 760 SW 2d 408 (1988), affirmed, 110 Sup Ct 2841 (1990).

21. Meisel I. The Right to Die, Volume 2. Wiley Law Publications, New York. 1995: 605

22. Westchester County Medical Ctr (O'Connor), 531 NE 2d 607 (NY 1988).

23. Re Grant, 747 P.2d 445, 458 (Wash 1987), modified, 757 P. 2d 534 (Wash 1988).

24. Representation Agreement Act, SBC 1993, c 67

25. Personal Directives Act, SA1996, c P-4.03.

26. Health Care Directives and Consequential Amendments Act, SM 1992, c 33.

27. Health Care Consent Act, SO 1996, c 31.

28. Substitute Decisions Act, SO 1992, c 30, am by 1994, c 27 ss 43(2), 62; 1996, c2 ss 3-60.

29. Art 12 CCQ.

30. Medical Consent Act, RSNS 1989 c 279.

31. Consent to Treatment and Health Care Directives Act, Stats PEI 1996, c 10

32. Advanced Health Care Directives Act, SN 1995, c A-4.1.
33. Singer P, Robertson G, Roy D. Advance care planning. CMAJ 1996; 155: $1689-1692$

34. Lazar N, Greiner G, Robertson G, Singer P. Substitute decisionmaking. CMAJ 1996; 155: 1435-1437.

35. Alberta Law Reform Institute. Advance directives and substitute decision-making in health care. Edmonton: The Institute, 1991. Report for discussion no 11.

36. Robertson GB. Mental disability and the law in Canada, 2nd ed. Toronto: Carswell, 1994

37. Rasooly I, Lavery J, Urowitz S, et al. Hospital policies on lifesustaining treatments and advance directives in Canada. CMAJ 1994; 150: 1265-1270.

38. Printz L. Terminal dehydration: a compassionate treatment. Arch Intern Med 1992; 152: 697-700.

39. Position of the American Academy of Neurology on certain aspects of the care and management of the persistent vegetative state patient: adopted by the executive board, American Academy of Neurology, April 1998, Cincinnati. Neurology 1989; 39: 125126.

40. American Medical Association, Council on Scientific Affairs and Council on Ethical and Judicial Affairs. Persistent vegetative state and the decision to withdraw or withhold life support. JAMA1990; 263: 426-430.

41. American Dietetic Association. Position of the American Dietetic Association: legal and ethical issues in feeding permanently unconscious patients. J Am Diet Assoc 1995; 95: 231-234.

42. Callahan C, Haag K, Buchanan N, et al. Decision-making for percutaneous endoscopic gastrostomy among older adults in a community setting. J Am Geriatr Soc 1999; 47: 1105-1109.

43. Ely J, Peters P, Zweig S, et al. The physician's decision to use tube feedings: the role of the family, the living will and the Cruzan decision. J Am Geriatr Soc 1992; 40: 471-475.

44. Mitchell S, Lawson F. Decision-making for long-term tube-feeding in cognitively impaired elderly people. CMAJ 1999; 160: 17051709 . 